\title{
Review of Offshore Cable Reliability Metrics
}

\author{
J. Warnock*, D. McMillan*, J. A. Pilgrim ${ }^{\dot{t}}$,S. Shenton ${ }^{\#}$ \\ *Wind Energy Systems Centre for Doctoral Training, University of Strathclyde, Glasgow \\ john.warnock@strath.ac.uk \\ ${ }^{+}$University of Southampton, Southampton \\ ${ }^{\#}$ Generating Better Limited, Workington
}

Keywords: Offshore, Cable, Reliability, Wind Energy.

\begin{abstract}
Reliable cable systems are essential for offshore wind operation. Industry trends have led to a large number of offshore cable connections being installed recently, with 11027 MW of offshore wind connected at the end of 2015 compared to just $2955 \mathrm{MW}$ in 2010 [1]. Despite the increase in connections, the publically available reliability data in this area is almost non-existent. With several connections in planning of both similar and increasing lengths it is essential to better understand these metrics.
\end{abstract}

A review of published reliability data was undertaken in order to populate a database which is presented in this paper. This data focusses on a number of connection types including both $\mathrm{AC}$ and DC connections across a number of cable ratings and configurations. From this database it is confirmed that reliability figures currently being used across the literature generally conform to those currently being experienced in the offshore wind industry. However it is established that failure rates taken from some reports are not accurate as the technology and environments these are calculated from are typically different from those used in offshore wind farm connections. This information is collated and converted into reliability metrics in order for comparisons to be made.

Analysis of the cost of an outage experienced by a windfarm is also carried out in this paper. The results of which establish that the revenue lost from a cable failure could potentially be substantial. The findings in this paper would also suggest a greater risk of failure in the early life of a windfarm and as such a greater potential cost associated with this risk.

It is important to have a better understanding of offshore renewable energy cable connections as the reliability of a cable has a significant impact on the Levelised Cost of Energy. With a greater understanding of the metrics investors can make more informed decisions with respect to the technology that is installed as well as the importance of the installation process itself, due diligence on subsequent OFTO asset purchases and the maintenance plans that have been outlined for the connection.

\section{Introduction}

With the increasing number of offshore wind farms as well as other renewable energy sources, such as wave and tidal, the need for greater subsea cable reliability is ever increasing. One of the key issues being faced is that the connections that are in planning are those of Round 3 wind farms which are significantly further offshore than the wind farms that have been installed already. This brings with it its own challenges such as, greater cable lengths, conflicts in opinion of which cable technology should be implemented and many different obstacles that are associated with the changes in the sea bed, amongst many others.

One of the most important challenges that are met early in the process is that of cable installation. There are many complex aspects of the processes before, during and after installation many of which can lead to significant failures if not managed correctly. Some reports [2] suggest that issues arising during the installation of cables are resulting in early life failures which then fall under the responsibility of the OFTO to repair.

If literature is examined it can be seen that reliability figures and failure data from offshore cables is sparse. As a result of this a number of authors have had to estimate failure rates such as the figures found in [3] which creates an estimate based on other literature, [4-6] which estimate failure rates through observation of onshore transmission reliability data and [7] which estimates a failure rate through discussion with cable manufacturers.

Some literature such as [8] uses reliability data found in CIGRE reports $[9,10]$. The data in the CIGRE reports is drawn from several cables reaching a total of over $7,000 \mathrm{~km}$ in length and of varying cable ratings. These cables are typically found in deeper water and used as interconnectors which are different from those used in offshore wind transmission. The use of this data in offshore cable connections to windfarms is investigated and discussed later in this paper.

There is a need for cable failure statistics to be made available. With this interested parties such as wind farm developers, prospective OFTO asset investors and $3^{\text {rd }}$ parties involved in due diligence and maintenance services could perform detailed reliability analysis as well as analyse the costs associated with a prospective failure. This could not only allow for better installation practice, leading to reduced outages and greater revenue but also help achieve cost 


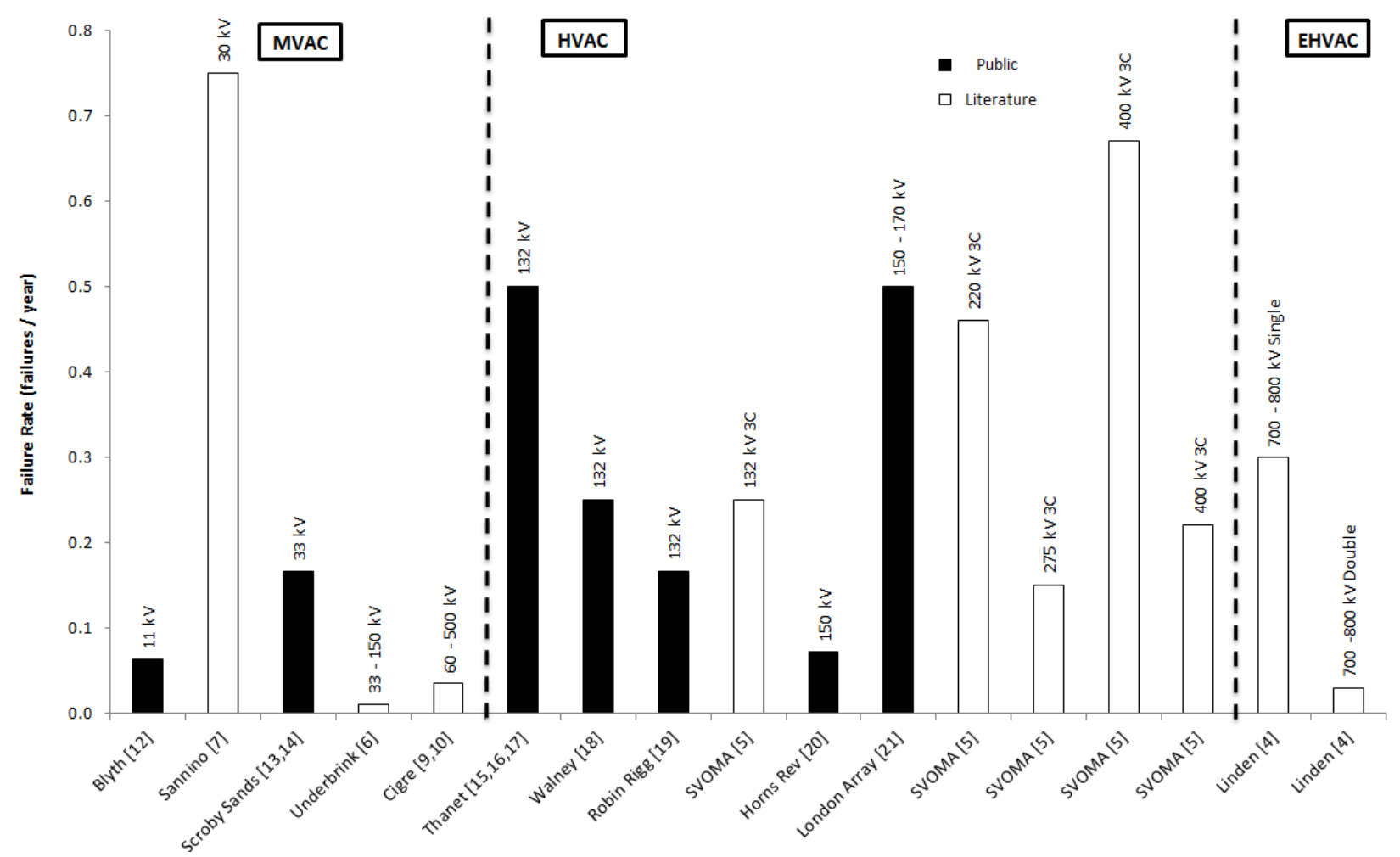

Figure 1: Failure Rate Data from Literature and Public Data

reduction targets set by both the UK and EU governments related to climate change and renewable energy.

\section{Analysis}

In order to populate the database shown in Table 2 a number of papers and reports which focussed on reliability analysis and offshore cables were reviewed [3-10]. The reliability figures used were then converted from a number of different formats to be represented as failures / year in order to allow for comparison between different cable lengths and ratings.

In order to represent the data in such a way, the figures that were presented as failures / $\mathrm{km} /$ year had to be allocated a length. In some cases the information was aggregated from more than $7,000 \mathrm{~km}$ of cable $[9,10]$. As the research involved both $\mathrm{AC}$ and $\mathrm{DC}$ cables of a number of different ratings the decision was made to allocate a cable length of $50 \mathrm{~km}$. This was chosen for this study as sources cite this as the 'cut-off' point at which a cable installer should opt for DC instead of AC from a cost-benefit perspective [11]. Recently industry trends have tended towards use of HVAC for lengths greater than $50 \mathrm{~km}$ and as such this study could be repeated for greater cable lengths in order to replicate some of the longer $\mathrm{AC}$ cables that are found offshore.

Publically available data on offshore cable failures was then investigated, revealing failure data that did not appear to be present throughout the literature. This information was collated through investigation of news articles [12 - 25],
Notice to Mariners / SeaFish reports [26]. This information was gathered and analysed to populate figure 1 .

\section{Results}

Once a reliability database had been constructed - as shown in Table 2 - the different reliability metrics could then be plotted and discussed. The chart in Figure 1 shows the different failure rates that have been drawn from each source with the black bars representing data taken from news articles and other publically available sources and the white bars representing the failure rates taken from papers and reports.

It can be seen that when considering medium voltage AC (MVAC) cables the estimation made in the paper by Sannino et al. [7] appears to overestimate the failure rate compared to that which has been observed by wind farms with similar ratings such as Scroby Sands. However the estimations made in the analysis carried out by Underbrink et al. [6] appears to underestimate the failure rate across both MVAC and High Voltage AC (HVAC), which may be as a result of basing their estimations on onshore cable reliability statistics.

When considering HVAC offshore transmission it can be seen that the estimations by Svoma et al. [5] are fairly representative of the failure rates experienced by current HVAC sites that have been operating for more than 3 years. Those sites which have been operating for less than 3 years, shown in Table 3, have been omitted from this comparison as the reliability performance of cables in early operation can 
deviate from the long term average behaviour shown in figure 1. This is discussed further in 3.1.

When considering Extra High Voltage AC (EHVAC) no meaningful comparisons can be made due to a lack of EHVAC sites currently offshore.

The data taken from the CIGRE report also spans across a range of voltages. As mentioned previously the cables which were analysed in this report were in excess of 7,000 km in length and most likely inhabit a different environment from that which an offshore windfarm transmission cable would, such as deeper waters where less movement of the cable would occur post installation. These factors all contribute to the small failure rate that is observed, because of this as well as reasons discussed later in the paper it is considered unwise to use this data in offshore windfarm connection reliability analysis.

\subsection{Cable Reliability over Time}

The latter entries in Table 3 show that there is a higher instance of transmission cable failures in the early life of windfarms, particularly in the first $2-3$ years. The method for calculating the failure rate was as follows:

\section{Number of Failures/Number of Years Operational}

This meant that for all early life windfarms the failure rate would be higher than that for an older wind farm that had experienced a similar number of failures.

An explanation for a high rate of failure in new installations can be found in [27], in which Steisdal and Madsen investigate reliability of offshore wind components. The authors take a conventional bathtub curve and determine that in practice the bathtub curve is not always applicable. The paper discusses infant mortality, random failures, wear out failures and premature mortality failures in order to plot the overall failure curve for offshore wind components.

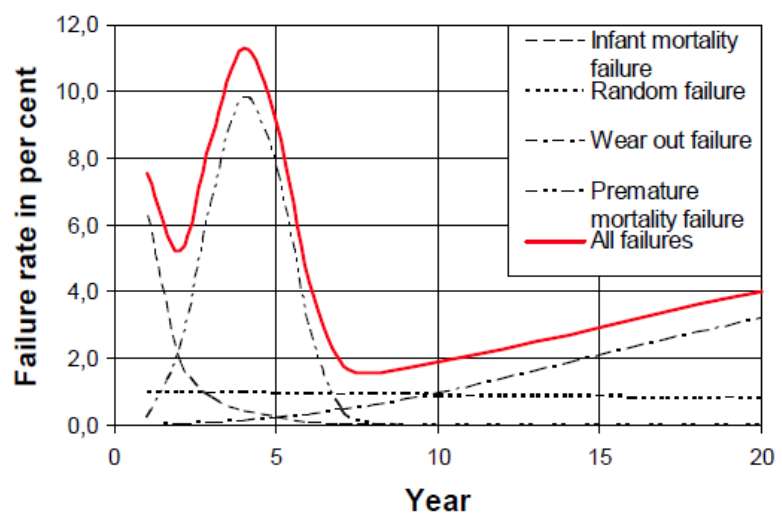

Figure 2: Augmented Failure Curve [27]

Figure 2 illustrates that in the early life of an offshore wind turbine there is an increased likelihood of component failure due to a number of factors. This may also be the case for offshore transmission lines.

Sites in the infant mortality phase may experience a higher number of failures; the physical reasons for these failures are investigated further in section 3.2.

\subsection{Cause of Failures}

Several reports such as those published by CIGRE $[9,10]$ suggest that the leading cause of offshore cable failures are as a result of fishing. This is primarily cited as being due to anchors and trawling however it appears that for offshore wind export cables, the underlying causes are different.

Fishing remains a risk to some submarine cables, especially if they become exposed, good communication processes to inform the fishing community and specialist Fisheries Liaison Officers are mitigating this risk which is borne out in the data analysed [26].

A number of the failures are listed as being manufacturing faults. These failures are often detected in the early stages of installation as they become apparent when the cable is energised.

Despite this publically available data listing some key causes of failures there is a lack of information on the root cause of failure in many cases. In some cases the downtime may have been as a result of a proactive repair (following knowledge about other cables from the same source). Other recorded outages may not be failures at all, but instead a short downtime due pro-active replacement of cable sections believed to be at risk, or outages due to non-cable related issues. However without transparency from windfarm owners and OFTOs this is difficult to validate.

A number of faults become clear shortly after the installation phase once the cable has become energised but before handover into operations. An example of this would be operation of jack up vessels performing turbine installation, damaging power cables already laid. This not only damages the cable through the initial impact but can result in the cable being pushed more than 20 metres into the substrate, both known causes of cable failures.

Cable installation can also lead to a number of faults depending on the nature and location of the installation. This is also dependent on the level of protection that is given to the cable post burial, such as whether the cable is buried, covered with rocks or concrete blankets or left to move freely on the ocean floor. In shallower waters there tends to be greater movement in both the water and the substrate. This can lead to a cable moving to a different location from where it was laid, which could mean the cable could become damaged by the seabed itself. Fishing reports such as Kingfisher [26] suggest that almost every site has some cable that is exposed or cable that is at risk, which again forces owners and 
operators to make decisions about running a cable which is at higher risk of fault.

\subsection{Comparison with CIGRE Results}

Throughout the review period reports that were often cited were those completed by CIGRE working groups, namely B1.10 and B1.21 [9,10]. As can be seen from Figure 1, whilst the data taken from these reports covers a large range of cable ratings the derived failure rates appear to be much smaller than all of the failure rates that were observed from operational wind farm export cables.

This is most likely due to the type of cables that were analysed for these reports. In many cases the cables analysed in these reports were interconnectors, spanning hundreds of miles and in deep water. Given the differences in the assets being analysed, it is unsurprising to see the reliability metrics diverging as seen in Figure 1.

The data from these reports has been used in a number of papers, which as can be seen from Figure 1 will result in an underestimation of failure rate metrics.

When considering wind farm or other renewable energy subsea connections, which generally occur in shallower water in which greater movement of the cable on the seabed will be observed usage of the metrics from the existing CIGRE reports should be treated with caution.

\section{Cost of an Outage}

The cost of a cable failure can be substantial as not only does the cost of the repair need to be accounted for, the lost revenue from generation must be accounted for. This cost may not only be substantial but could also vary significantly depending on the nature of the failure and the time at which the failure occurs.

A number of factors must be considered when determining the cost of any given failure offshore, not only those which occur on cable systems. The key contributors to the length of an outage will be availability of vessels and replacement parts, as well the time of year when the outage occurs. Each of these factors will vary depending on the depth of the water and distance from shore at which the failure occurs. The repair costs associated with each individual failure will also be dependent on each of these factors.

\subsection{Calculation of the Cost of an Outage}

In order to estimate the average monthly cost of an outage for an offshore wind farm a number of assumptions were made: the size of the windfarm was estimated based on current offshore windfarm sizes. The availability figure was assumed to be $95 \%$ as the report by The Crown Estate [28] states that offshore windfarm availability is $90-95 \%$. The Crown Estate also state in [29] that the average capacity factor in 2015 was
$39.8 \%$. Information on the wholesale price of energy and buy out price of ROCs was taken from [30] and [31] respectively.

\begin{tabular}{|c|c|}
\hline Size of Windfarm & $300 \mathrm{MW}$ \\
\hline Availability [28] & $95 \%$ \\
\hline Capacity Factor [29] & $39.8 \%$ \\
\hline Wholesale Price of Electricity [30] & $£ 46.01 / \mathrm{MWh}$ \\
\hline Buyout Price of ROCs [31] & $£ 44.33$ \\
\hline Offshore Wind ROC Banding [32] & $1.9 / \mathrm{MWh}$ \\
\hline
\end{tabular}

Table 1: Cost of Outage Assumptions

Using these values the average electricity produced each month could be calculated:

$$
\begin{gathered}
\text { Electricity Produced }= \\
\text { Windfarm Rating } * \text { Avg. Hours in a month } \\
* \text { Capacity Factor } * \text { Availability }
\end{gathered}
$$

This calculation approximated the average electricity generated by a $300 \mathrm{MW}$ offshore windfarm in MWh. Using this value the revenue generated by this windfarm could then be calculated.

$$
\begin{aligned}
& \text { Revenue }=(\text { Electricity Produced } \\
& * \text { Wholesale Price of Electricty }) \\
& +(\text { Electricity Produced } * 1.9 \\
& * \text { Buyout Price of ROCs })
\end{aligned}
$$

Given that the ROC banding for offshore wind is currently 1.9 per MWh of electricity produced.

The value of the average electricity produced per month was estimated to be:

$$
£ 10,784,131.52
$$

If a fault were to occur that were to stop generation for a month, this would be the overall loss of revenue. In winter months the time to repair can be in excess of 3 or 4 months which could lead to a more significant loss in revenue for windfarm operators and owners.

A 300MW windfarm would typically have two cable connections to shore and as such the revenue lost would be less than the figure estimated above if there was a fault on only one of the transmission lines. If a loss of $50 \%$ of generation was assumed due to a fault on one cable the lost revenue would be approximately $£ 5.4$ million per month.

\section{Conclusions}

This paper has presented a comparison between the failure rate data presented throughout literature. This details the differences that can be seen depending on the source material and highlights that these differences could have a significant impact upon the outcome of any reliability analysis that is undertaken using these failure rates.

The paper then compares these failure rates to failure rates extrapolated from press releases and other publically available data. In this comparison it is seen that whilst some 
estimates are fairly accurate there are some that deviate from the failure rates observed in operation offshore windfarms.

During the literature review it became clear that one of the primary sources from which failure rates were taken was the CIGRE reports $[9,10]$. Given the results of this review it was determined that these values should be treated with caution in the analysis of offshore wind farm cables. It was deduced that the information in these reports was derived from large interconnector like cables which would typically be installed in different environments than current and planned windfarm connections such as deep steady water compared to shallow water with a greater deal of movement by the cable.

Finally a short section regarding the cost of an outage was presented to illustrate the significance of an outage. It is important to note that the assumed losses are around $£ 5.4$ million per month and some failures to export cables have been reported to last as long as 5 or 6 months $[15,33]$, although could typically span 3 months if the failure occurs in the winter.

With all of these points considered alongside the assumptions that cable failures could be several times more common than reported it should be clear that there is a need for greater levels of transparency from all parties involved in offshore wind repairs and reliability.

Future work aims to build upon the findings discussed in this paper in order to further establish a means for categorising failures using data found in the public domain. There is also scope for further analysis on the true cost of any given cable failure.

\section{Acknowledgements}

The authors acknowledge the support of the UK Engineering and Physical Sciences Research Council and the University of Strathclyde's Wind Energy Systems Centre for Doctoral Training, grant number EP/G037728/1

\section{References}

[1] A. Ho, A. Mbistrova, G. Corbetta. "The European offshore wind industry key trends and statistics 2015”, EWEA (2016)

[2] KPMG. "Offshore Transmission: An Investor Perspective", (2012).

[3] C. MacIver, K. R. W. Bell and D. P. Nedic, "A Reliability Evaluation of Offshore HVDC Grid Configuration Options." University of Strathclyde, (2013).

[4] K. Linden, B. Jacobson, M. H. J. Bollen, J. Lundquist. "Reliability study methodology for HVDC grids," presented at the Cigré Paris Session, paper B4-108, Paris, (2010).

[5] R. Svoma, M. Dickinson, C. Brown. "Subsea connections to high capacity offshore windfarms", $19^{\text {th }}$ International Conference on Electricity Distribution, Vienna, (2007).

[6] A. Underbrink, J. Hansen, A. Osterholt, W. Zimmerman. "Probabilistic Reliability Calculations for the Grid Connection of and Offshore Wind Farm", 9th International Conference on Probabilistic Methods Applied to Power Systems, Stockholm, (2006).
[7] A. Sannino, H. Breder, E. Nielsen. "Reliability of Collection Grids for Large offshore Wind Parks", 9th International Conference on Probabilistic Methods Applied to Power Systems, Stockholm, (2006).

[8] Sinclair Knight Merz. "Calculating Target Availability Figures for HVDC Interconnectors", ofgem, (2012).

[9] CIGRE working group B1.10. "Update of service experience of HV underground and submarine cables", (2009).

[10] CIGRE working group B1.21. "Third-Party Damage to Underground and Submarine Cables", (2009).

[11] A. B. Morton, S. Cowdroy, J. R. A. Hill, M. Halliday, G. D. Nicholson. "AC or DC? Economics of grid connection design for offshore wind farms", $8^{\text {th }}$ IEE International Conference on AC and DC Power Transmission, (2006).

[12] http://news.bbc.co.uk/1/hi/england/norfolk/7190082.stm accessed on $05 / 10 / 2016$

[13] http://news.bbc.co.uk/1/hi/england/norfolk/7190082.stm accessed on $05 / 10 / 2016$

[14] http://news.bbc.co.uk/1/hi/england/7290290.stm accessed on 05/10/2016

[15] http://www.windpoweroffshore.com/article/1191497/thanetcable-failure-cost-vattenfall-\%E2\%82\%AC5m Accessed on $06 / 10 / 2016$

[16] http://www.windpoweroffshore.com/article/1323873/balfourbeatty-awarded-thanet-transmission-licence accessed on 05/10/2016 [17] http://www.4coffshore.com/windfarms/remedial-worksunderway-for-thanet-nid4649.html accessed on 05/10/2016

[18] http://www.4coffshore.com/windfarms/pharos-recovers-faultywalney-cable-nid3389.html accessed on 05/10/2016

[19]

https://www.ofgem.gov.uk/sites/default/files/docs/tc_robin_rigg_-

_direction_under_paragraph_10_of_amended_standard_condition_e 12-j4.pdf accessed on 05/10/2016

[20] http://www.windpoweroffshore.com/article/1368848/horns-rev2-cable-failure-confirmed-tso-updated accessed on 05/10/2016

[21] http://www.sunwindenergy.com/news/cable-damage-britishoffshore-wind-farms accessed on 05/10/2016

[22] http://www.4coffshore.com/windfarms/anholt-cable-defectsnid1355.html accessed on 05/10/2016

[23] http://www.4coffshore.com/windfarms/walney-2-no-go-sincefriday-nid2963.html accessed on 05/10/2016

[24] http://www.vbms.com/en/projects/detail/gwynt-y-mor-cablerepair accessed on 05/10/2016

[25] http://gymofto.co.uk/docs/Investor\%20Report\%20\%20March\%202015.pdf accessed on 05/10/2016

[26] http://www.seafish.org/industry-support/kingfisher-informationservices accessed on 14/10/16

[27] H. Stiesdal, P. H. Madsen, "Design for reliability," Proc. Copenhagen Offshore Wind. International Conference, Copenhagen, Denmark, (2005).

[28] The Crown Estate. "A Guide to UK Offshore Wind Operations and Maintenance", (2013).

[29] The Crown Estate. "Offshore wind operational report", (2015)

[30] "http://www.energybrokers.co.uk/electricity/historic-price-datagraph.htm" Accessed on 05/10/2016

[31] The Renewables Obligation buy-out price and mutualisation ceiling 2014-15 accessed via "https://www.ofgem.gov.uk/publications-and-updates/renewablesobligation-buy-out-price-and-mutualisation-ceiling-2014-15" on $06 / 10 / 2016$

[32]

https://www.gov.uk/government/uploads/system/uploads/attachment _data/file/211292/ro_banding_levels_2013_17.pdf accessed on $14 / 10 / 2016$

[33] http://www.sunwindenergy.com/news/cable-damage-britishoffshore-wind-farms accessed on 17/10/2016 


\section{Appendix}

\begin{tabular}{|c|c|c|c|c|}
\hline Technology & Cable Rating & Failure rate (failures/year) & Year & Reference \\
\hline \multirow{3}{*}{ HVDC } & \multirow{3}{*}{$320 \mathrm{kV}$} & Best: 0.00001107 & \multirow{3}{*}{2015} & \multirow{3}{*}{$\begin{array}{l}\text { A Reliability Evaluation of Offshore } \\
\text { HVDC Grid Configuration Options [3] }\end{array}$} \\
\hline & & Middle: 0.00002213 & & \\
\hline & & Worst: 0.0003689 & & \\
\hline HVAC & $60-500 \mathrm{kV}$ & 0.000000101 & 2012 & $\begin{array}{l}\text { Calculating Target Availability Figures } \\
\text { for HVDC Interconnectors [8] / Update } \\
\text { of service experience of HV }\end{array}$ \\
\hline HVDC & $60-500 \mathrm{kV}$ & 0.000000163 & & and Submarine Cables [10] \\
\hline \multirow{2}{*}{ EHVAC } & \multirow{2}{*}{$700-800 \mathrm{kV}$} & Single Circuit: 0.3 & \multirow{4}{*}{2010} & \multirow{4}{*}{$\begin{array}{l}\text { Reliability study methodology for } \\
\text { HVDC grids [4] }\end{array}$} \\
\hline & & Double Circuit: 0.03 & & \\
\hline \multirow{2}{*}{ HVDC } & \multirow{2}{*}{$600-650 \mathrm{kV}$} & Single Pole: 0.4 & & \\
\hline & & Double Pole: 0.03 & & \\
\hline \multirow{5}{*}{ HVAC } & 132 kV 3 Core & 0.25 & \multirow{5}{*}{2007} & \multirow{5}{*}{$\begin{array}{l}\text { Subsea connections to high capacity } \\
\text { offshore windfarms [5] }\end{array}$} \\
\hline & 220 kV 3 Core & 0.46 & & \\
\hline & 400 kV 3 Core & 0.67 & & \\
\hline & 275 kV Single Core & 0.15 & & \\
\hline & 400 kV Single Core & 0.22 & & \\
\hline \multirow{3}{*}{ MVAC } & \multirow{3}{*}{$30 \mathrm{kV}$} & Feeder Cable: 0.003 & \multirow{3}{*}{2006} & \multirow{3}{*}{$\begin{array}{l}\text { Reliability of Collection Grids for Large } \\
\text { offshore Wind Parks [7] }\end{array}$} \\
\hline & & Tower - Tower Cable: 0.0125 & & \\
\hline & & Tower Cable: 0.1875 & & \\
\hline \multirow{2}{*}{$\mathrm{M} / \mathrm{HVAC}$} & \multirow{2}{*}{$33-150 \mathrm{kV}$} & Submarine: 0.00000467 & \multirow{2}{*}{2006} & \multirow{2}{*}{$\begin{array}{c}\text { Probabilistic Reliability Calculations for } \\
\text { the Grid Connection of and Offshore } \\
\text { Wind Farm [6] }\end{array}$} \\
\hline & & Inter-Array: 0.0000323 & & \\
\hline
\end{tabular}

Table 2: Failure Rate Data from Literature

\begin{tabular}{|c|c|c|c|c|}
\hline Technology & Cable Rating & Failure rate (failures/year) & Year & Reference \\
\hline MVAC & $11 \mathrm{kV}$ & 0.0625 & $2000-2016$ & Blyth [12] \\
\hline MVAC & $33 \mathrm{kV}$ & 0.167 & $2004-2016$ & Thanet [15,16,17] \\
\hline HVAC & $132 \mathrm{kV}$ & 0.5 & $2010-2016$ & Walney [18] \\
\hline HVAC & $132 \mathrm{kV}$ & 0.25 & $2012-2016$ & Robin Rigg [19] \\
\hline HVAC & $132 \mathrm{kV}$ & 0.167 & $2010-2016$ & Horns Rev [20] \\
\hline HVAC & $150 \mathrm{kV}$ & 0.0714 & $2012-2016$ & London Array [21] \\
\hline HVAC & $150-170 \mathrm{kV}$ & 0.5 & $2013-2016$ & Anholt [22] \\
\hline HVAC & $220-245 \mathrm{kV}$ & 1 & $2015-2016$ & Walney 2 [23] \\
\hline HVAC & $132 \mathrm{kV}$ & 1 & $2015-2016$ & Gwynt Y Mor [24,25] \\
\hline HVAC & $132 \mathrm{kV}$ & 3 & & \\
\hline
\end{tabular}

Table 3: Publically Available Failure Rate Data 